Research Article

\title{
Three-Party Stochastic Evolutionary Game Analysis of Reward and Punishment Mechanism for Green Credit
}

\author{
Qingfeng Zhu $\mathbb{D}^{1,2}$ Kaimin Zheng $\mathbb{D}^{1},{ }^{1}$ and Yilin Wei ${ }^{1}{ }^{1}$ \\ ${ }^{1}$ School of Mathematics and Quantitative Economics, Shandong University of Finance and Economics, Jinan 250014, China \\ ${ }^{2}$ Shandong Key Laboratory of Blockchain Finance, Jinan 250014, China \\ Correspondence should be addressed to Kaimin Zheng; 192113013@mail.sdufe.edu.cn
}

Received 20 February 2021; Revised 22 March 2021; Accepted 3 June 2021; Published 17 June 2021

Academic Editor: Ruguo Fan

Copyright (C) 2021 Qingfeng Zhu et al. This is an open access article distributed under the Creative Commons Attribution License, which permits unrestricted use, distribution, and reproduction in any medium, provided the original work is properly cited.

To get rid of the development dilemma of green credit, we constructed a stochastic evolutionary game model of local government, commercial banks, and loan enterprises. We gave sufficient conditions for the stability of strategy based on the stability discriminant theorem of Itô's stochastic differential equation (SDE). Then, we discussed the impacts of incentive and penalty parameters on green credit. Through the above analysis, we got the following conclusions: (1) rewards and punishments always benefit green production and green credit, but increasing incentives is not conducive to the governments' performance of regulatory duties; (2) punishments can better improve the convergence rate of players' strategy than rewards; and (3) both rewards and punishments can exert an obvious effect in improving the changing degree of players' strategy. Finally, we put forward some suggestions to optimize the green credit mechanism.

\section{Introduction}

Green credit means that financial institutions provide loan support and preferential treatment to the enterprises, which satisfy the national industrial policy and environmental protection standards, and restrict or refuse to lend to other enterprises with heavy pollution and high energy consumption. As an effective way to develop green finance, green credit plays an important role in expanding green enterprises and promoting the transformation and upgrading of the economic structure. In order to pursue green development, since 2007, the People's Bank of China (PBOC) and China Banking Regulatory Commission (CBRC) have begun to promote the establishment of a green credit standard system framework and successively issued a number of green credit-related systems. The major systems include the Green Credit Guidelines and Guiding Opinions on Building a Green Financial System. In May 2020, in Premier Keqiang Li's government work report, he stressed out that it is necessary to innovate financial instruments such as green credit, expand applicable business scenarios, increase the proportion of green projects, and further promote ecological environmental governance.

To promote the construction of ecological civilization and realize the sustainable development of the economy, China has attached great importance to the development of green credit and encouraged more social capital to flow into the green industry [1-4]. However, in China, the green credit policy is an oriented policy at the initial stage of exploration. Although the scale of green credit continues to expand, there are still some financial institutions and enterprises which lack environmental awareness and social responsibility. In addition, many market participants are susceptible to the absence of supervision and profit motive, so that they could make certain short-sighted behaviors [5]. Thus, the development of green credit has the problem of insufficient impetus.

The green credit market possesses obvious characteristics of the game. Under the framework of game theory, many scholars have conducted research on the interests relationship among green credit participants. Xue et al. [6] used several game models to explore the effective ways in which commercial banks develop green credit business. Wang et al. 
[7] and $\mathrm{Li}$ [8] introduced the intervention of financial regulatory authorities into the evolutionary game and analyzed the influence of supervision behavior in the implementation of green credit. Zhou et al. [9] established an evolutionary game model of the government, bank, and enterprise and pointed out that the rewards and punishments of the government and the green credit of the bank can encourage enterprises to adopt green supply chains. Furthermore, some researchers contend that government or regulatory authorities should increase penalties for polluting enterprises and improve the incentive and restraint mechanism for banks to better promote green credit $[10,11]$. The defect of these existing documents is twofold. First, most studies involved only two players, and little research focused on the three-party game of government, commercial banks, and loan enterprises. Second, although a few scholars used evolutionary game models to make a detailed analysis, they ignored uncertainty in the implementation of green credit and failed to reflect the impact of random disturbance on the decision-making of participants.

In the earlier period, some scholars have captured the existence of high uncertainty in the objective world and considered it in the study of game theory. Foster et al. [12] first put forward the concept of stochastic evolutionary game and pointed out that the stochastically stable strategy (SSS) should be robust not only for a small amount of deviation but also for random mutation. In recent years, the analysis mechanism of the dynamics of finite population stochastic evolutionary game has been gradually improved $[13,14]$. Currently, Gaussian white noise is widely applied to the replication dynamic equation of evolutionary game, which is used to investigate the group's strategy selection under the random disturbance of the external environment. Xu et al. [15] used the stochastic evolutionary game model to study the subject behavior in the strategic alliance and got sufficient conditions for the stability and disintegration of the alliance. Sun et al. [16] applied the stochastic evolutionary game model to study group emergencies and analyzed the stability of the behavioral strategies of the disadvantaged and powerful groups in an uncertain environment. Miao et al. [17] used Itô's stochastic differential equation (SDE) containing white noise to study the game behavior of owners and contractors in major projects, which provided corresponding suggestions for risk management in major projects. Based on the stochastic evolutionary game, He et al. [18] analyzed the steady-state and convergence rate of the evolution process of industry-university-institute collaboration innovation and provided relevant improvement measures for solving the synergy problem. Li et al. $[19,20]$ constructed a stochastic evolutionary game model around the R\&D manipulation phenomenon in the application of high-tech enterprises and discussed the effectiveness of variable adjustment through simulation. Therefore, the stochastic evolutionary game has been applied to many fields.

In this context, we construct a three-party stochastic evolutionary game model of local governments, commercial banks, and loan enterprises. The contribution of this study is reflected in the following two aspects: first, the three-party stochastic evolutionary game model is applied to the behavior research of green credit transaction subjects, and the sufficient conditions for the stability of subject strategy are given under uncertain environment; second, the impact of key parameters on the convergence rate and the changing degree of players' strategy is comparatively analyzed by numerical simulation, and the effectiveness of reward and punishment mechanism is further discussed.

The structure of this paper is as follows: in Section 2, we describe the framework of the evolutionary game model in green credit. In Section 3, we introduce random disturbance factors and establish a stochastic evolutionary game model. In Section 4, we present the numerical simulation results and analyze the impact of key parameters. In Section 5, we provide the conclusions and management implications of this paper.

\section{Green Credit Evolutionary Game Model}

The concept of "evolutionary game" was first proposed by Smith [21]. It can well reflect the process in which participants with bounded rationality reach equilibrium through slow learning and continuous adjustment in reality [22], which is similar to the behavioral characteristics of participants in green credit implementation. Therefore, this study adopts the evolutionary game method to analyze the strategic choices of green credit participants and identify their decision motivations and evolution laws.

2.1. Model Hypothesis. We assume that, in the implementation of green credit, there are three main players-local government (including regulatory agency), commercial banks, and loan enterprises. Based on evolutionary game theory, the following hypotheses are made for the three players:

Hypothesis 1. The strategy that can be taken by the local government (including regulatory agency) is "nonsupport" or "support," and the probability of action selection of it is $x$ and $1-x, 0 \leq x \leq 1$. On the one hand, the local government may fail to supervise and intervene in green credit policies for the sake of local fiscal revenue and performance appraisal, that is, they do not support the development of green credit. At this time, the government obtained tax revenue $T$ from the loan enterprises, but it will be punished by the superior government and the supervisory department for failing to perform its service and supervisory duties. The punishment is marked as $\beta P_{1}$, where $\beta$ represents the degree of punishment, $0 \leq \beta \leq 1$, and $P_{1}$ represents the amount of punishment to the local government in the worst cases. On the other hand, the local government may actively respond to the country's call for green development, formulate strong measures of awards and punishment, and implement green credit policies, that is, supporting the development of green credit. At this point, in order to supervise the banks implementing green credit and the enterprises adopting green production, the supervision cost of the local government is $G$. If the banks provide preferential interest rate for green production enterprises, the government's financial 
subsidies they can get are $\gamma S$, where $\gamma$ represents the degree of subsidies, $0 \leq \gamma \leq 1$. Meanwhile, the enterprises that adopt green production can also get a certain proportion of tax reduction, and the taxes they pay are $(1-\alpha) T$, where $\alpha$ is the tax reduction ratio.

Hypothesis 2. The strategy that can be taken by the commercial banks is "nonperformance" or "performance," and the probability of action selection of it is $y$ and $1-y$, $0 \leq y \leq 1$. If the bank does not implement the green credit policy in pursuit of operating profit, it will obtain loan interest income $R_{1}$ from all loan enterprises at the ordinary interest rate, but it will be also punished by the local government or superior government with a penalty amount $\beta P_{2}$. Conversely, if the bank implements the green credit policy, it will investigate the qualifications of the loan enterprise, and the audit cost will be $D$. At this time, the bank will obtain the loan interest income $R_{1}$ from the nongreen production enterprises at the ordinary interest rate and obtain the loan interest income $R_{2}$ from the green production enterprises at the preferential interest rate, $R_{2}<R_{1}$. Meanwhile, the bank will also earn a certain green reputation $F$ because of the good image of taking social responsibility.

Hypothesis 3. The action that can be taken by the loan enterprises is "nongreen production" or "green production," and the probability of action selection of it is $z$ and $1-z$, $0 \leq z \leq 1$. In order to reduce governance costs and pursue commercial profits, enterprises may adopt nongreen production; they will be punished by local government or superior government with a penalty amount $\beta P_{3}$ because of environmental pollution. Enterprises may also adopt green production so as to obtain preferential loan interest rates. At this time, they need to invest in energy conservation and emission reduction costs $C_{1}$. In addition, the operating income of the enterprises is $E$, and other operating costs are $\mathrm{C}_{2}$.

Based on the above analysis and parameter setting, we can get the specific payoff matrix of local government, bank, and loan enterprise, as shown in Table 1.

2.2. Construction of Evolutionary Game Model. Assuming that the expected income of the "nonsupport" or "support" strategies adopted by the local government is $U_{11}$ and $U_{12}$, respectively, the average expected income of local government is $\bar{U}_{1}$. Then,

$$
\begin{aligned}
U_{11}= & y z\left(T-\beta P_{1}\right)+y(1-z)\left(T-\beta P_{1}\right)+(1-y) z\left(T-\beta P_{1}\right) \\
& +(1-y)(1-z)\left(T-\beta P_{1}\right)=T-\beta P_{1},
\end{aligned}
$$

$$
\begin{aligned}
U_{12}= & y z(T-G)+y(1-z)[(1-\alpha) T-G] \\
& +(1-y) z(T-G) \\
& +(1-y)(1-z)[(1-\alpha) T-G-\gamma S] \\
= & T-G-(1-z) \alpha T-(1-y)(1-z) \gamma S,
\end{aligned}
$$

$\bar{U}_{1}=x U_{11}+(1-x) U_{12}$.

According to equations (1)-(3), the replication dynamic equation [23] of the local government can be further obtained as follows:

$$
\begin{aligned}
\frac{\mathrm{d} x}{\mathrm{~d} t} & =x\left(U_{11}-\bar{U}_{1}\right) \\
& =x(1-x)\left[G+(1-z) \alpha T+(1-y)(1-z) \gamma S-\beta P_{1}\right] .
\end{aligned}
$$

Assuming that the expected income of the "nonperformance" or "performance" strategies adopted by the bank is $U_{21}$ and $U_{22}$, respectively, the average expected income of the bank is $U_{2}$. Then,

$$
\begin{aligned}
U_{21}= & x z R_{1}+x(1-z)\left(R_{1}-\beta P_{2}\right)+(1-x) z R_{1} \\
& +(1-x)(1-z)\left(R_{1}-\beta P_{2}\right)=R_{1}-(1-z) \beta P_{2}, \\
U_{22}= & x z\left(R_{1}-D+F\right)+x(1-z)\left(R_{2}-D+F\right) \\
& +(1-x) z\left(R_{1}-D+F\right) \\
& +(1-x)(1-z)\left(R_{2}-D+F+\gamma S\right) \\
= & F-D+z R_{1}+(1-z) R_{2}+(1-x)(1-z) \gamma S, \\
\bar{U}_{2}= & y U_{21}+(1-y) U_{22} .
\end{aligned}
$$

The replication dynamic equation of the bank can be further expressed as follows:

$$
\begin{aligned}
\frac{\mathrm{d} y}{\mathrm{~d} t}= & y\left(U_{21}-\bar{U}_{2}\right) \\
= & y(1-y)\left[(1-z)\left(R_{1}-R_{2}\right)-F+D-(1-z) \beta P_{2}\right. \\
& -(1-x)(1-z) \gamma S] .
\end{aligned}
$$


TABLE 1: Payoff matrix of local government, bank, and loan enterprise.

\begin{tabular}{|c|c|c|c|}
\hline Strategic combination & Local government & Bank & Loan enterprise \\
\hline $\begin{array}{l}\text { (Nonsupport, nonperformance, nongreen production) } \\
\text { (Nonsupport, nonperformance, green production) } \\
\text { (Nonsupport, performance, nongreen production) } \\
\text { (Nonsupport, performance, green production) } \\
\text { (Support, nonperformance, nongreen production) } \\
\text { (Support, nonperformance, green production) } \\
\text { (Support, performance, nongreen production) } \\
\text { (Support, performance, green production) }\end{array}$ & $\begin{array}{c}T-\beta P_{1} \\
T-\beta P_{1} \\
T-\beta P_{1} \\
T-\beta P_{1} \\
T-G \\
(1-\alpha) T-G \\
T-G \\
(1-\alpha) T-G-\gamma S\end{array}$ & $\begin{array}{c}R_{1} \\
R_{1}-\beta P_{2} \\
R_{1}-D+F \\
R_{2}-D+F \\
R_{1} \\
R_{1}-\beta P_{2} \\
R_{1}-D+F \\
R_{2}-D+F+\gamma S\end{array}$ & $\begin{array}{c}E-T-R_{1}-C_{2}-\beta P_{3} \\
E-T-R_{1}-C_{1}-C_{2} \\
E-T-R_{1}-C_{2}-\beta P_{3} \\
E-T-R_{2}-C_{1}-C_{2} \\
E-T-R_{1}-C_{2}-\beta P_{3} \\
E-(1-\alpha) T-R_{1}-C_{1}-C_{2} \\
E-T-R_{1}-C_{2}-\beta P_{3} \\
E-(1-\alpha) T-R_{2}-C_{1}-C_{2}\end{array}$ \\
\hline
\end{tabular}

Similarly, assuming that the expected income of the "nongreen production" or "green production" strategies adopted by the loan enterprise is $U_{31}$ and $U_{32}$, respectively, the average expected income of loan enterprise is $\bar{U}_{3}$. Then,

$$
\begin{aligned}
U_{31}= & x y\left(E-T-R_{1}-C_{2}-\beta P_{3}\right) \\
& +x(1-y)\left(E-T-R_{1}-C_{2}-\beta P_{3}\right) \\
& +(1-x) y\left(E-T-R_{1}-C_{2}-\beta P_{3}\right) \\
& +(1-x)(1-y)\left(E-T-R_{1}-C_{2}-\beta P_{3}\right) \\
= & E-T-R_{1}-C_{2}-\beta P_{3}, \\
U_{32}= & x y\left(E-T-R_{1}-C_{1}-C_{2}\right) \\
& +x(1-y)\left(E-T-R_{2}-C_{1}-C_{2}\right) \\
& +(1-x) y\left[E-(1-\alpha) T-R_{1}-C_{1}-C_{2}\right] \\
& +(1-x)(1-y)\left[E-(1-\alpha) T-R_{2}-C_{1}-C_{2}\right] \\
= & E-T-C_{1}-C_{2}-y R_{1}-(1-y) R_{2}+(1-x) \alpha T, \\
\bar{U}_{3}= & z U_{31}+(1-z) U_{32} .
\end{aligned}
$$

The replication dynamic equation of the loan enterprise can be further obtained as follows:

$$
\begin{aligned}
\frac{\mathrm{d} z}{\mathrm{~d} t} & =z\left(U_{31}-\bar{U}_{3}\right) \\
& =z(1-z)\left[C_{1}-\beta P_{3}-(1-y)\left(R_{1}-R_{2}\right)-(1-x) \alpha T\right] .
\end{aligned}
$$

Since $1-x, 1-y$, and $1-z$ are all nonnegative and will not affect the results of the evolutionary game, the replication dynamic equations of local government, bank, and loan enterprise are transformed into the following form [16]:

$$
\begin{aligned}
\mathrm{d} x= & x\left[G+(1-z) \alpha T+(1-y)(1-z) \gamma S-\beta P_{1}\right] \mathrm{d} t \\
\mathrm{~d} y= & y\left[(1-z)\left(R_{1}-R_{2}\right)-F+D-(1-z) \beta P_{2}\right. \\
& -(1-x)(1-z) \gamma S] \mathrm{d} t, \\
\mathrm{~d} z= & z\left[C_{1}-\beta P_{3}-(1-y)\left(R_{1}-R_{2}\right)-(1-x) \alpha T\right] \mathrm{d} t .
\end{aligned}
$$

\section{Green Credit Stochastic Evolutionary Game Model}

3.1. Construction of Stochastic Evolutionary Game Model. During the implementation of green credit, the game among the government, bank, and loan enterprise faces great uncertainty. On the one hand, in addition to the production and operation status of enterprises, the emotional changes and risk preferences of each group will directly affect the strategies of the players. On the other hand, external factors such as changes in the credit system and macroeconomic policies will also interfere with the behavior of players. Therefore, the original evolutionary game cannot truly reflect the strategic adjustment process of each participant in green credit. In order to overcome this flaw, it is necessary to add random factors to the evolutionary game model. In this paper, Gaussian white noise is introduced into the replication dynamic equations:

$$
\begin{aligned}
\mathrm{d} x(t)= & x(t)\left[G+(1-z) \alpha T+(1-y)(1-z) \gamma S-\beta P_{1}\right] \mathrm{d} t \\
& +\sigma x(t) \mathrm{d} \omega(t) \\
\mathrm{d} y(t)= & y(t)\left[(1-z)\left(R_{1}-R_{2}\right)-F+D-(1-z) \beta P_{2}\right. \\
& -(1-x)(1-z) \gamma S] \mathrm{d} t+\sigma y(t) \mathrm{d} \omega(t), \\
\mathrm{d} z(t)= & z(t)\left[C_{1}-\beta P_{3}-(1-y)\left(R_{1}-R_{2}\right)-(1-x) \alpha T\right] \mathrm{d} t \\
& +\sigma z(t) \mathrm{d} \omega(t) .
\end{aligned}
$$

In this equation, $\sigma$ represents the intensity of random disturbance and $\omega(t)$ represents one-dimensional standard Brownian motion. The Brownian motion represents a random fluctuation phenomenon, and it can well reflect the influence of random disturbance in the evolution of groups. $\mathrm{d} \omega(t)$ is Gaussian white noise, when $t>0$ and time step $h>0$, $\omega(t+h)-\omega(t) \sim N(0, h)$.

3.2. Stability Analysis of Evolutionary Equilibrium Solution. Assuming that the initial moment is $t=0$, the initial values are $x(0)=0, y(0)=0$, and $z(0)=0$, and we can find that $x(t)=0, y(t)=0$, and $z(t)=0$ are the equilibrium solutions of equations (10)-(12). That is, without external interference, the system will always stay in the state where the local government chooses "support," the bank chooses "performance," and the loan enterprise chooses "green production." However, due to the high uncertainty in the real world, it is often impossible to achieve this ideal situation, and each group member will always be more or less disturbed by random factors. Thus, it is necessary to consider the influence of random disturbance on the stability of the system. The sufficient criterion for the stability of the SDE is 
given below $[24,25]$, and the stability of strategy selection is judged.

Theorem 1. A stochastic differential equation is given as

$$
\begin{aligned}
\mathrm{d} x(t) & =f(t, x(t)) \mathrm{d} t+g(t, x(t)) \mathrm{d} \omega(t), \\
x\left(t_{0}\right) & =x_{0} .
\end{aligned}
$$

Let $x(t)=x\left(t, x_{0}\right)$ be the solution of equation (13), given a continuously differentiable function $V(t, x)$ and positive constants ; there exists $c_{1}|x|^{p} \leq V(t, x) \leq c_{2}|x|^{p}, t \geq 0$. Let $L V(t, x)=V_{t}(t, x)+V_{x}(t$,

$x) f(t, x)+(1 / 2) g^{2}(t, x) V_{x x}(t, x)$ :

(1) If there is a positive constant $\gamma$, which satisfies $L V(t, x) \leq-\gamma V(t, x), t \geq 0$, then the zero solution $p$-th moment of equation (13) is exponentially stable, and $E\left|x\left(t, x_{0}\right)\right|^{p}<\left(c_{2} / c_{1}\right)\left|x_{0}\right|^{p} e^{-\gamma t}, t \geq 0$.

(2) If there is a positive constant $\gamma$, which satisfies $L V(t, x) \geq \gamma V(t, x), t \geq 0$, then the zero solution $\mathrm{p}$-th moment of equation (13) is exponentially unstable, and $E\left|x\left(t, x_{0}\right)\right|^{p} \geq\left(c_{2} / c_{1}\right)\left|x_{0}\right|^{p} e^{-\gamma t}, t \geq 0$.

For equations (10)-(12), let $V(t, x)=x, V(t, y)=y$, $V(t, z)=z, c_{1}=1, c_{2}=1, p=1$, and $\gamma=1$; then, $L V(t$, $x)=f(t, x), L V(t, y)=f(t, y)$, and $L V(t, z)=f(t, z)$. If the zero solution $p$-th moment exponential of equations (10)-(12) is stable, it needs to satisfy

$$
\begin{gathered}
x\left[G+(1-z) \alpha T+(1-y)(1-z) \gamma S-\beta P_{1}\right] \leq-x \\
y\left[(1-z)\left(R_{1}-R_{2}\right)-F+D-(1-z) \beta P_{2}\right. \\
-(1-x)(1-z) \gamma S] \leq-y \\
z\left[C_{1}-\beta P_{3}-(1-y)\left(R_{1}-R_{2}\right)-(1-x) \alpha T\right] \leq-z .
\end{gathered}
$$

According to $x, y, z \in[0,1]$, equations (14)-(16) are reduced correspondingly, and three sufficient conditions are obtained to satisfy the above equations:

$$
\begin{gathered}
G+\alpha T+\gamma S-\beta P_{1}+1 \leq 0, \\
R_{1}-R_{2}+D-F+1 \leq 0, \\
C_{1}-\beta P_{3}+1 \leq 0 .
\end{gathered}
$$

When the above three conditions (17)-(19) are satisfied at the same time, the zero solution $p$ - th moment exponential of equations (10)-(12) is stable. This means that, as the time goes on, the proportion of noncooperative strategies (the local government chooses "nonsupport," the bank chooses "nonperformance," and the loan enterprise chooses "nongreen production") will exponentially decay to zero. At this time, the only evolutionarily stable strategy [26] is a cooperative strategy (the local government chooses "support," the bank chooses "performance," and the loan enterprise chooses "green production").

\section{Numerical Simulation and Analysis}

4.1. Stochastic Taylor Expansion of Replication Dynamic Equation. Since equations (10)-(12) are all nonlinear Itô's SDEs, it is impossible to directly obtain the analytical solutions, so the stochastic Taylor expansion is used to solve the equations numerically. For simplicity, we first discuss the following Itô's SDEs:

$$
\mathrm{d} x(t)=f(t, x(t)) \mathrm{d} t+g(t, x(t)) \mathrm{d} \omega(t) .
$$

In this equation, $t \in\left[t_{0}, T\right], x\left(t_{0}\right)=x_{0}, x_{0} \in R$, and $\omega(t)$ represent one-dimensional standard Brown motion. Let $h=$ $\left(\left(T-t_{0}\right) / N\right), t_{n}=t_{0}+n h$, the stochastic Taylor expansion of equation (20) can be obtained as follows:

$$
\begin{aligned}
x\left(t_{n+1}\right)= & x\left(t_{n}\right)+h f\left(x\left(t_{n}\right)\right)+\Delta \omega_{n} g\left(x\left(t_{n}\right)\right) \\
& +\frac{1}{2}\left[\left(\Delta \omega_{n}\right)^{2}-h\right] g\left(x\left(t_{n}\right)\right) g^{\prime}\left(x\left(t_{n}\right)\right) \\
& +\frac{1}{2} h^{2}\left[f\left(x\left(t_{n}\right)\right) f^{\prime}\left(x\left(t_{n}\right)\right)\right. \\
& \left.+\frac{1}{2} g^{2}\left(x\left(t_{n}\right)\right) f^{\prime \prime}\left(x\left(t_{n}\right)\right)\right]+R .
\end{aligned}
$$

In the above expansion, $R$ is the remainder term.

This paper adopts the Milstein numerical method [27] to solve the equations. In the Milstein method, the stochastic Taylor expansion is truncated into a first-order expression and the remainder term is discarded. Therefore, equation (21) is modified as follows:

$$
\begin{aligned}
x\left(t_{n+1}\right)= & x\left(t_{n}\right)+h f\left(x\left(t_{n}\right)\right)+\Delta \omega_{n} g\left(x\left(t_{n}\right)\right) \\
& +\frac{1}{2}\left[\left(\Delta \omega_{n}\right)^{2}-h\right] g\left(x\left(t_{n}\right)\right) g^{\prime}\left(x\left(t_{n}\right)\right) .
\end{aligned}
$$

Therefore, the Milstein method can be used to numerically solve the SDEs (10)-(12) in the three-party green credit game, and we can obtain 


$$
\begin{aligned}
x\left(t_{n+1}\right)= & x\left(t_{n}\right)+h x\left(t_{n}\right)\left[G+\left(1-z\left(t_{n}\right)\right) \alpha T\right. \\
& \left.+\left(1-y\left(t_{n}\right)\right)\left(1-z\left(t_{n}\right)\right) \gamma S-\beta P_{1}\right] \\
& +\Delta \omega_{n} \sigma x\left(t_{n}\right)+\frac{1}{2}\left[\left(\Delta \omega_{n}\right)^{2}-h\right] \sigma^{2} x\left(t_{n}\right), \\
y\left(t_{n+1}\right)= & y\left(t_{n}\right)+h y\left(t_{n}\right)\left[\left(1-z\left(t_{n}\right)\right)\left(R_{1}-R_{2}\right)-F+D-\left(1-z\left(t_{n}\right)\right) \beta P_{2}\right] \\
& +\Delta \omega_{n} \sigma y\left(t_{n}\right)+\frac{1}{2}\left[\left(\Delta \omega_{n}\right)^{2}-h\right] \sigma^{2} y\left(t_{n}\right), \\
z\left(t_{n+1}\right)= & z\left(t_{n}\right)+h z\left(t_{n}\right)\left[C_{1}-\beta P_{3}-\left(1-y\left(t_{n}\right)\right)\left(R_{1}-R_{2}\right)-\left(1-x\left(t_{n}\right)\right) \alpha T\right] \\
& +\Delta \omega_{n} \sigma z\left(t_{n}\right)+\frac{1}{2}\left[\left(\Delta \omega_{n}\right)^{2}-h\right] \sigma^{2} z\left(t_{n}\right) .
\end{aligned}
$$

According to equations (23)-(25), the numerical solution of the Itô's SDEs (10)-(12) can be realized, and the corresponding equilibrium solution can be obtained.

4.2. Parameters Sensitivity Analysis and Discussion. In this section, we use $R$ software (version: 3.6 .1 ) to simulate the stochastic evolutionary game model. We focus on the influence of the value change of incentive and penalty parameters on the evolution game results and attempt to evaluate their priority levels according to their influence degree. The variable assignment satisfies the sufficient condition of zero solution of equations (10)-(12) expectation moment exponentially stability. At this time, the local government is willing to provide support for green credit, commercial banks tend to implement green credit, and loan enterprises tend to adopt green production. In order to facilitate the simulation, we set the range of variables to $0-50$, and then assign values based on the relative size relationship of the variables in the actual situation. The values of the related variables are as follows: $P_{1}=50, P_{2}=10, P_{3}=$ 25, $G=0.5, T=5, S=1, C_{1}=1.4, R_{1}=8, R_{2}=6, D=5$, $F=9$. We set initial value $x(0)=0.5, y(0)=0.5, z(0)=$ 0.5 , simulation step length $h=0.01$ and random disturbance term $\sigma=2$.

4.2.1. Tax Reduction Ratio. Keeping the value of other parameters unchanged, the influence of the change of tax reduction ratio $\alpha$ on the strategic evolution path of local government and loan enterprise is analyzed. Let $\alpha=0.1$, 0.5 , and 0.9 , respectively, and the simulation results are shown in Figures 1 and 2. It is not difficult to observe that, for local government, as the proportion of tax cuts increases, the proportion of local governments that choose not to support green credit will increase slightly. This may be because the government tends to have a negative attitude towards green credit policies in consideration of fiscal revenue. However, the increase of $\alpha$ will cause the proportion of loan enterprises that choose nongreen production to drop significantly at many moments, that is, the greater the tax incentives, the higher the enthusiasm of enterprises to participate in green production.

From the perspective of the convergence rate of the strategy, the impact of increasing the tax reduction ratio $\alpha$ from 0.1 to 0.9 on the strategies of local government and loan enterprise is inconsistent. When $\alpha=0.1$, the moment when the proportion of local governments adopting nonsupport first reaches zero is $t=0.23$, but the moment when the proportion of loan enterprises adopting nongreen production first reaches zero is $t=0.44$. When $\alpha=0.9$, this moment becomes $t=0.28$ for local government, which is extended by 0.05 , while for loan enterprise, this moment becomes $t=0.39$, which is shortened by 0.05 . Increasing the proportion of tax cuts for green enterprise will make it later for local government to reach the state of full support, but it will make it earlier for loan enterprise to achieve the state of full green production. Therefore, when the relevant departments adjust $\alpha$, there will be a contradiction between the speed of the two players' strategies converging to zero, and relevant departments need to make some trade-off.

Next, we consider the changing degree of the strategy. The worst case of local government's strategy selection in the evolution process is that when $\alpha=0.9$, the proportion of local governments adopting nonsupport exceeds the initial proportion $50 \%$ and reaches the maximum value of $54.84 \%$ at the moment of $t=0.02$. But when $\alpha=0.1$, the proportion that local governments choose nonsupport can be reduced to $52.41 \%$ at this worst moment, which falls by $2.43 \%$. While for loan enterprises, the worst case occurs when $\alpha=0.1$, the proportion of loan enterprises choosing nongreen production reaches the maximum value of $72.85 \%$ at the moment of $t=0.03$, and when $\alpha$ is increased to 0.9 , this proportion can drop to $68.74 \%$, which falls by $4.11 \%$. Therefore, when relevant departments are committed to controlling the changing degree of the players' strategies by adjusting the tax reduction ratio, there is also some tradeoff in the regulatory measures for local government and loan enterprise. In general, when the impact of tax cuts on loan enterprises is prioritized, the regulatory effect is slightly better. 


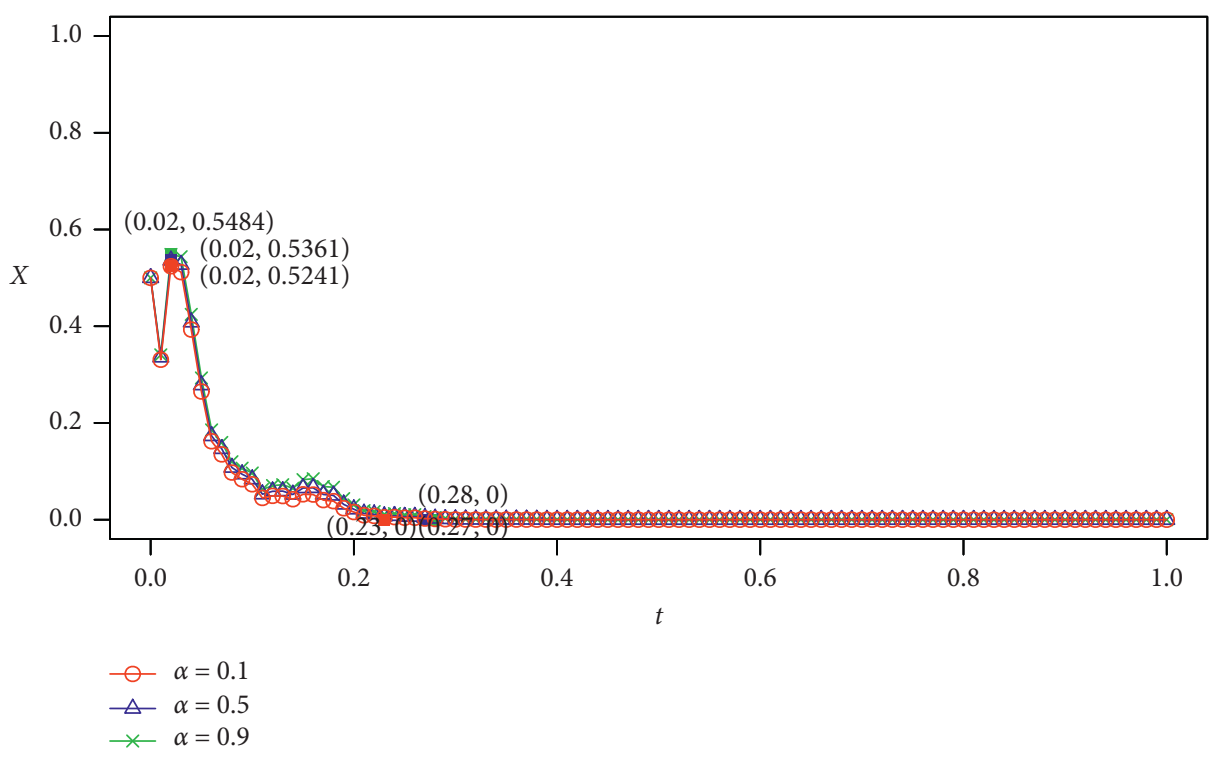

FIGURE 1: The impact of tax reduction ratio $\alpha$ on local government's strategy selection.

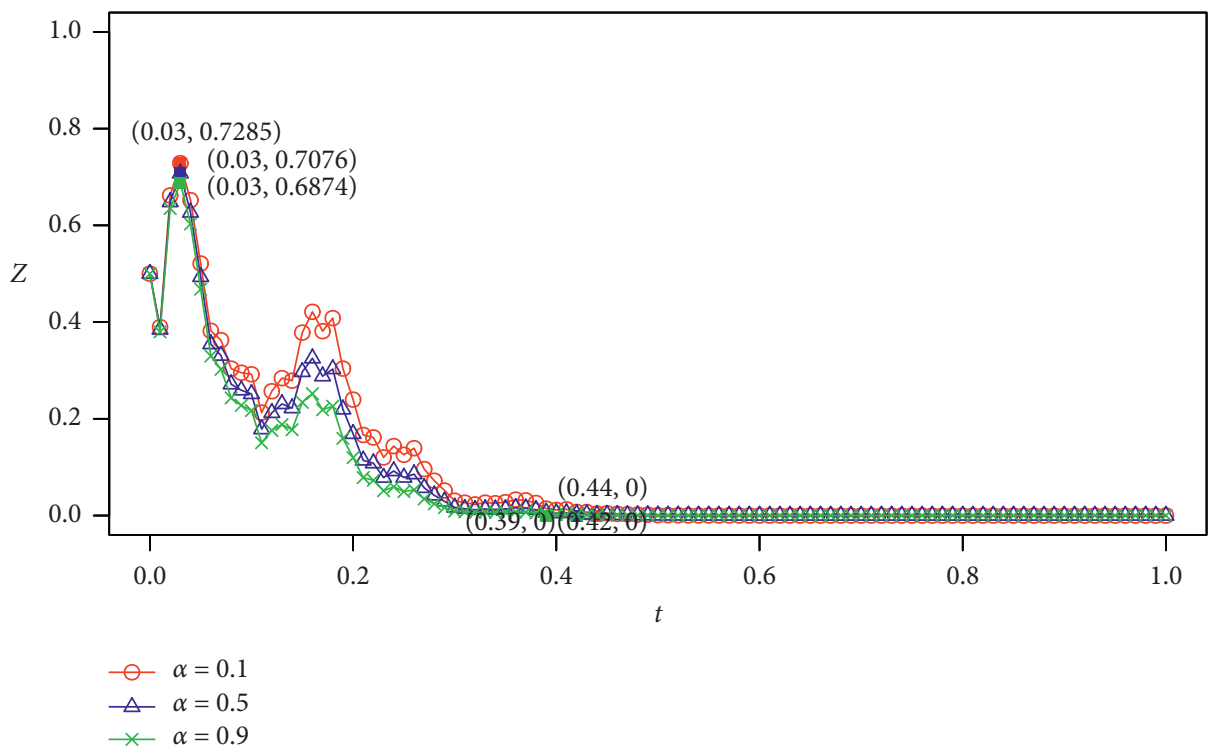

Figure 2: The impact of tax reduction ratio $\alpha$ on loan enterprise's strategy selection.

4.2.2. Degree of Financial Subsidies. Keeping the value of other parameters unchanged, let the degree of financial subsidies $\gamma=0.1,0.5$, and 0.9 , respectively, and the impact of $\gamma$ on local government and commercial bank is shown in Figures 3 and 4 . It can be found that, with the increase of $\gamma$, the proportion of local governments that choose nonsupport increases slightly, while the proportion of commercial banks that choose nonperformance drops significantly at many moments. The reason is that, as financial subsidies to commercial banks increase, the local government may be slightly inclined not to support green credit due to greater financial pressure, but commercial banks will obviously improve their enthusiasm for implementing green credit because of this incentive.
Considering the convergence rate of the strategy, it can be seen that when $\gamma=0.1$, the moment when the proportion of local governments adopting nonsupport first reaches zero is $t=0.27$, but the moment when the proportion of banks adopting nonperformance first reaches zero is $t=0.54$. When $\gamma=0.9$, this moment becomes $t=0.3$ for local governments, which is extended by 0.03 , while for commercial banks, this moment becomes $t=0.42$, which is shortened by 0.12 . Therefore, when the superior department is devoted to improving the convergence rate of players' strategies by adjusting the degree of financial subsidies, it will be more effective in prioritizing the control of commercial banks.

Then, we analyze the influence of $\gamma$ on the changing degree of the strategy. The worst case of local government's 


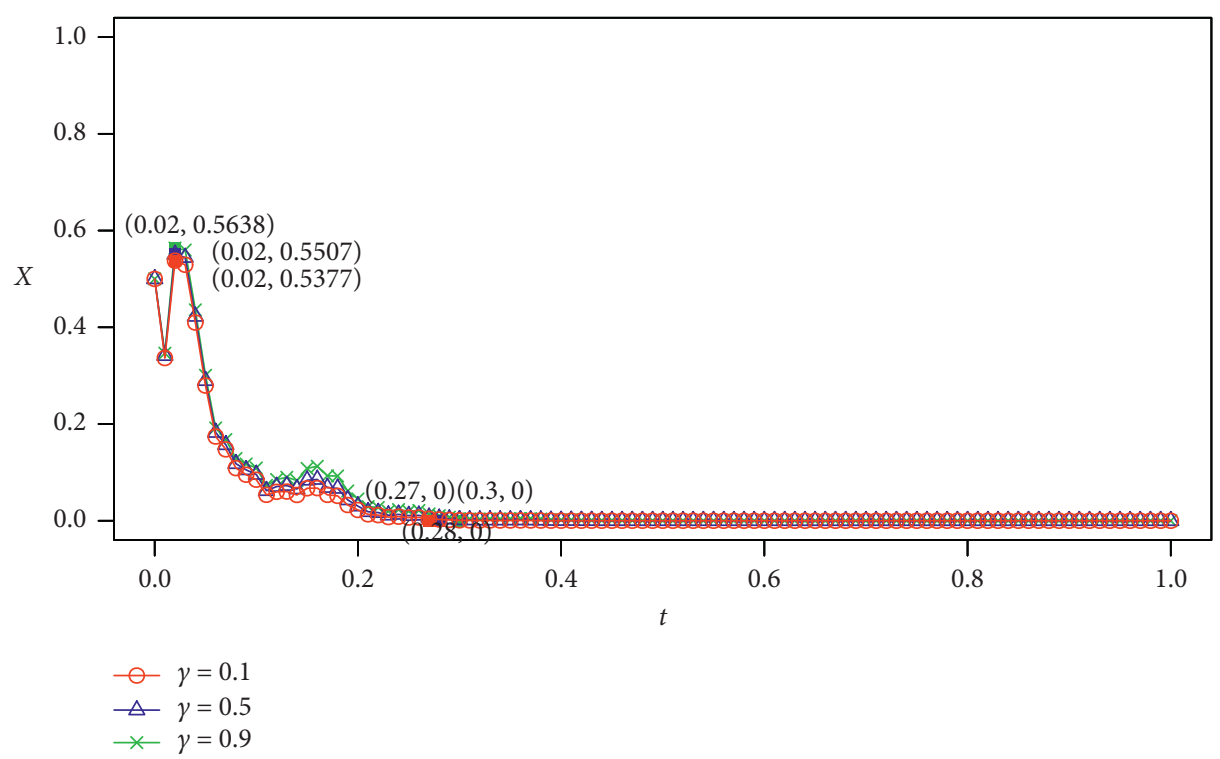

FIgURE 3: The impact of the degree of financial subsidies $\gamma$ on local government's strategy selection.

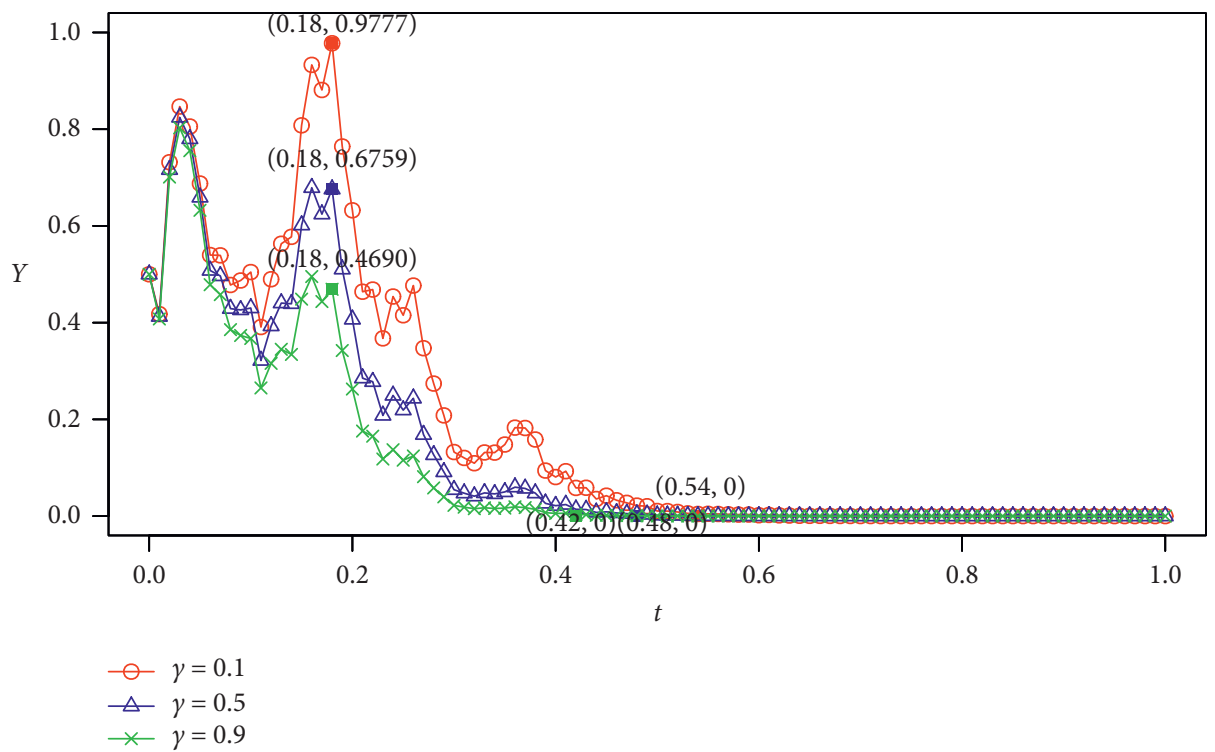

FIgURE 4: The impact of the degree of financial subsidies $\gamma$ on commercial bank's strategy selection.

strategy selection in the evolution process is that when $\gamma=0.9$, the proportion of local governments adopting nonsupport exceeds the initial proportion of $50 \%$ and reaches the maximum value of $56.38 \%$ at the moment of $t=0.02$. But when $\gamma=0.1$, this proportion can be reduced to $53.77 \%$, which falls by $2.61 \%$. While for loan enterprises, the worst case occurs when $\gamma=0.1$, the proportion of commercial banks choosing nonperformance reaches the maximum value of $97.77 \%$ at the moment of $t=0.18$, and when $\gamma$ is increased to 0.9 , this proportion can drop to $46.90 \%$, which significantly falls by $50.87 \%$. Therefore, it is pretty effective for relevant departments to increase the financial subsidies to banks if they want to improve the changing degree of the players' strategies.
4.2.3. Degree of Punishment. Similarly, keeping the value of other parameters unchanged, let the degree of punishment $\beta=0.1,0.5$, and 0.9 , respectively, and we can observe the impact of $\beta$ on local government, commercial bank, and loan enterprise. As can be seen from Figures 5-7, with the increase of the degree of punishment, the risk cost of the three parties also increases, and thus the proportion of noncooperative strategies decreased greatly.

Considering the convergence rate of the strategy, we can observe that when $\beta$ is increased from 0.1 to 0.9 , the moment when the proportion of local governments adopting nonsupport first reaches zero is reduced from $t=0.94$ to $t=0.09$, which is shortened by 0.85 , the moment when the proportion of commercial banks adopting nonperformance first 


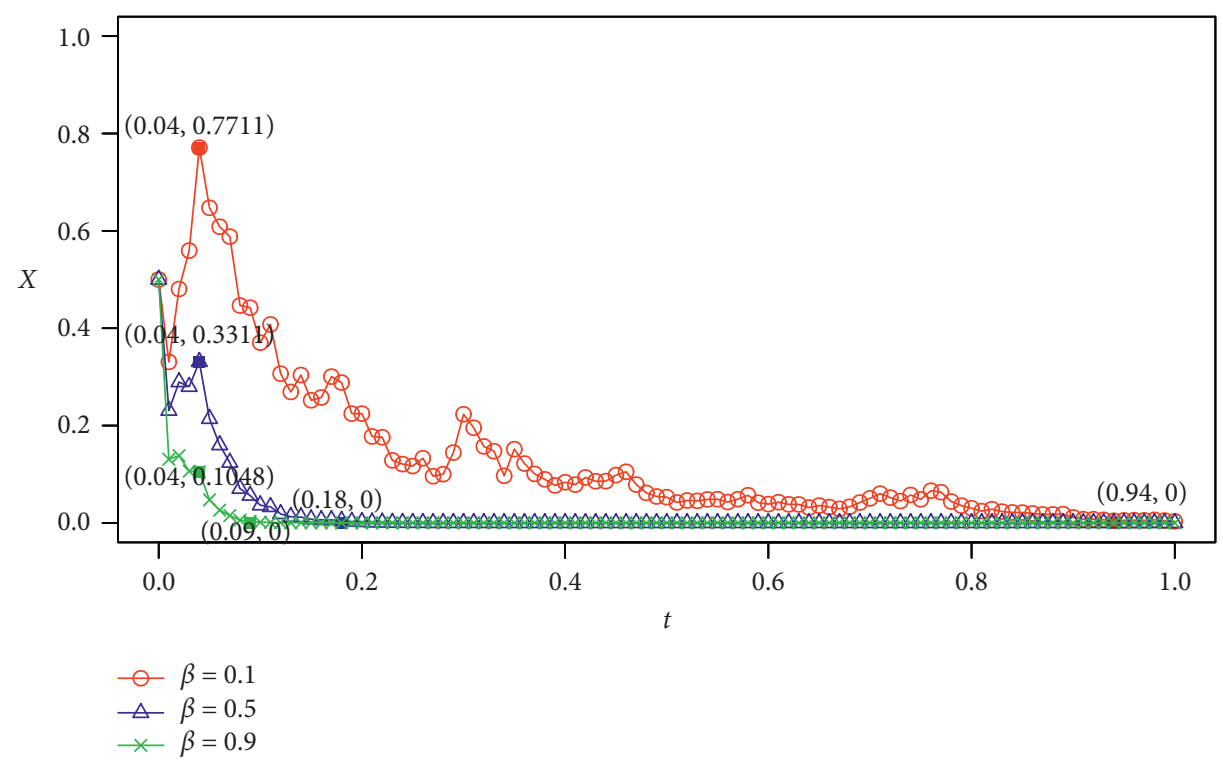

Figure 5: The impact of the degree of punishment $\beta$ on local government's strategy selection.

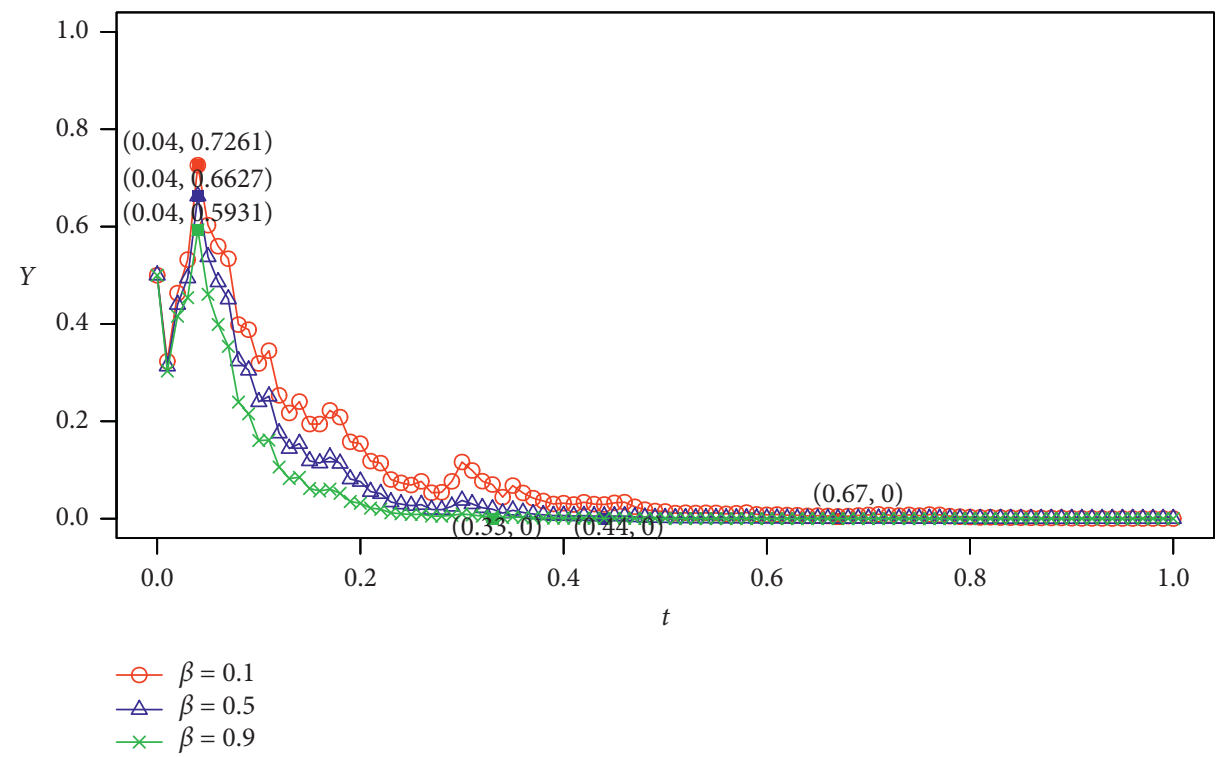

Figure 6: The impact of the degree of punishment $\beta$ on commercial bank's strategy selection.

reaches zero is reduced from $t=0.67$ to $t=0.33$, which is shortened by 0.34 , and the moment when the proportion of loan enterprises adopting nongreen production first reaches zero is reduced from $t=0.64$ to $t=0.15$, which is shortened by 0.49 . This shows that if the superior department wants to achieve the full cooperation state between the three parties more quickly by adjusting the degree of punishment, it will be more effective in increasing penalties for local governments.

Next, we focus on the impact of $\beta$ on the changing degree of the strategy. Take $t=0.04$ as an example, which is the moment when the proportion of noncooperation strategies reaches its maximum in the evolution progress. Increasing $\beta$ from 0.1 to 0.9 , the proportion of local governments adopting nonsupport is reduced from $77.11 \%$ to $10.48 \%$, which falls by $66.63 \%$; the proportion of commercial banks choosing nonperformance is reduced from $72.61 \%$ to $59.31 \%$, which falls by $13.30 \%$; and the proportion of loan enterprises adopting nongreen production is reduced from $75.83 \%$ to $31.38 \%$, which falls by $44.45 \%$. So, if relevant departments want to improve the changing degree of the players' strategies through punishment, the regulation effect of increasing the risk cost of local governments may be the most significant.

4.2.4. Discussion. Based on the simulation results, we comparatively analyze the impact of incentive and penalty parameters on the convergence rate and changing degree of subject strategy, as shown in Tables 2 and 3. 


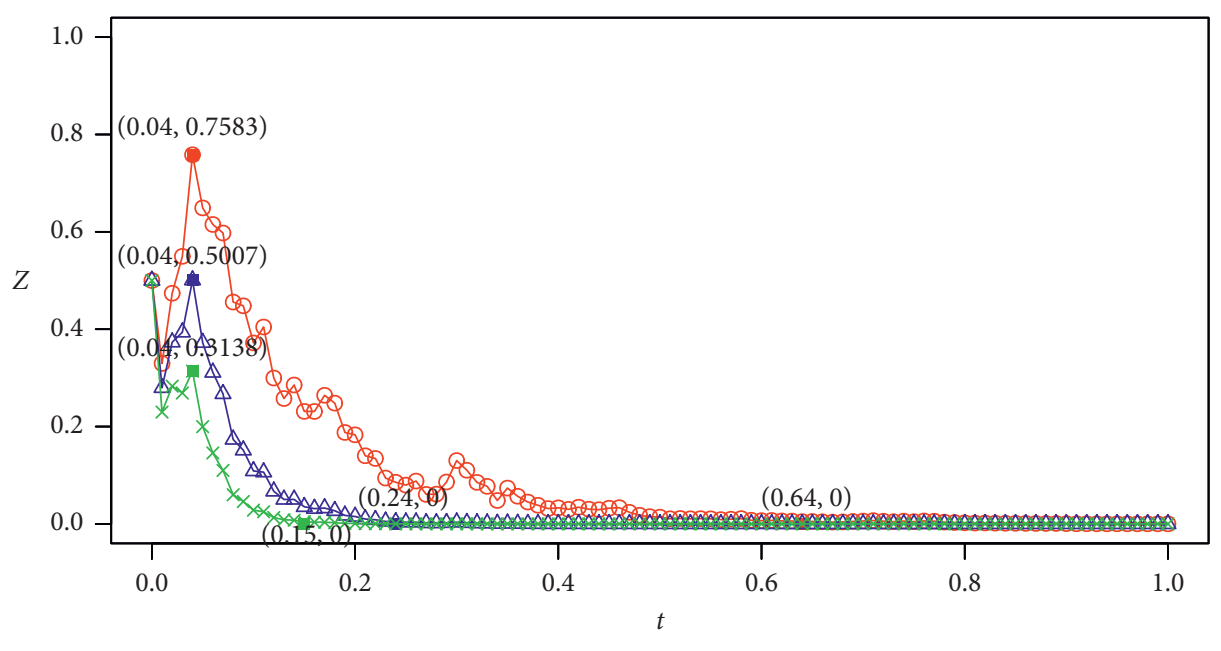

$$
\begin{aligned}
& -\beta=0.1 \\
& \triangle \beta=0.5 \\
& -\beta=0.9
\end{aligned}
$$

FIGURE 7: The impact of the degree of punishment $\beta$ on loan enterprise's strategy selection.

TABLE 2: Impact of incentive and penalty parameters on the convergence rate of subject strategy.

\begin{tabular}{lcr}
\hline Value of parameters & The moment of the proportion of noncooperative strategies first reaching zero & Change in convergence rate \\
\hline \multirow{2}{*}{$0.1 \longrightarrow 0.5 \longrightarrow 0.9$} & $t_{x}: 0.23 \longrightarrow 0.27 \longrightarrow 0.28$ & $\Delta t_{x}=0.05 \uparrow$ \\
& $t_{z}: 0.44 \longrightarrow 0.42 \longrightarrow 0.39$ & $\Delta t_{z}=0.05 \downarrow$ \\
\hline \multirow{2}{*}{$0.1 \longrightarrow 0.5 \longrightarrow 0.9$} & $t_{x}: 0.27 \longrightarrow 0.28 \longrightarrow 0.30$ & $\Delta t_{x}=0.03 \uparrow$ \\
& $t_{y}: 0.54 \longrightarrow 0.48 \longrightarrow 0.42$ & $\Delta t_{y}=0.12 \downarrow$ \\
\hline & $t_{x}: 0.94 \longrightarrow 0.18 \longrightarrow 0.09$ & $\Delta t_{x}=0.85 \downarrow$ \\
& $t_{y}: 0.67 \longrightarrow 0.44 \longrightarrow 0.33$ & $\Delta t_{y}=0.34 \downarrow$ \\
& $t_{z}: 0.64 \longrightarrow 0.24 \longrightarrow 0.15$ & $\Delta t_{z}=0.49 \downarrow$ \\
\hline
\end{tabular}

\begin{tabular}{|c|c|c|}
\hline Value of parameters & Maximum proportion of noncooperative strategies & Change in strategy proportion \\
\hline$\alpha: 0.1 \longrightarrow 0.5 \longrightarrow 0.9$ & $\begin{array}{l}x(0.02): 52.41 \% \longrightarrow 53.61 \% \longrightarrow 54.84 \% \\
z(0.03): 72.85 \% \longrightarrow 70.76 \% \longrightarrow 68.74 \%\end{array}$ & $\begin{aligned} \Delta x & =2.43 \% \uparrow \\
\Delta z & =4.11 \% \downarrow\end{aligned}$ \\
\hline$\gamma: 0.1 \longrightarrow 0.5 \longrightarrow 0.9$ & $\begin{array}{l}x(0.02): 53.77 \% \longrightarrow 55.07 \% \longrightarrow 56.38 \% \\
y(0.18): 97.77 \% \longrightarrow 67.59 \% \longrightarrow 46.90 \%\end{array}$ & $\begin{array}{c}\Delta x=2.61 \% \uparrow \\
\Delta y=50.87 \% \downarrow\end{array}$ \\
\hline$\beta: 0.1 \longrightarrow 0.5 \longrightarrow 0.9$ & $\begin{array}{l}x(0.04): 77.11 \% \longrightarrow 33.11 \% \longrightarrow 10.48 \% \\
y(0.04): 72.61 \% \longrightarrow 66.27 \% \longrightarrow 59.31 \% \\
z(0.04): 75.83 \% \longrightarrow 50.07 \% \longrightarrow 31.38 \%\end{array}$ & $\begin{array}{l}\Delta x=66.63 \% \downarrow \\
\Delta y=13.30 \% \downarrow \\
\Delta z=44.45 \% \downarrow\end{array}$ \\
\hline
\end{tabular}

TABLE 3: Impact of incentive and penalty parameters on the changing degree of subject strategy.

As shown in Table 2, when the superior department is committed to improving the convergence rate of subject strategy so as to realize full cooperation state more quickly, compared with other parameters, the three players are more sensitive to the change in the degree of punishment. Thus, increasing the punishment on noncooperative players and raising their risk costs can greatly shorten the time to achieve the stable state, which is more effective than the adjustment of incentive parameters. Therefore, considering the convergence rate of subject strategy, the effect of the punishment mechanism is better.

As can be seen from Table 3, when the relevant department pays more attention to the changing degree of subject strategy, it is not difficult to find that, compared with other subjects and parameters, local government and loan enterprises are more sensitive to the change in the degree of punishment. Meanwhile, commercial banks are also highly sensitive to the change in the degree of financial subsidies. Thus, the authority should impose severe punishment on the government that adopts nonsupport strategy and the enterprises that adopt nongreen production strategy and increase the financial subsidies to commercial banks, which can significantly increase the proportion of participants choosing cooperative strategies. Therefore, taking into account the changing degree of subject strategy, reward mechanism and punishment mechanism can both achieve good results. 


\section{Conclusions and Management Implications}

In this paper, we constructed a stochastic evolutionary game model of local government, commercial bank, and loan enterprise. The sufficient conditions for the stability of the subject strategy are given, and the influence of incentive and penalty parameters on the convergence rate and changing degree of players' strategy is analyzed by simulation. Through the analysis of the model results, we got some important conclusions and management implications as follows.

First, the strengthening of reward and punishment by local governments can help banks implement green credit policy and enterprises choose green production mode, but increasing incentives is not conducive to the governments' own performance of regulatory duties. When the local government increases tax reduction ratio to the green enterprises and increases financial subsidies to the commercial banks that carry out green credit business, although it can effectively increase the enthusiasm of enterprises to adopt green production and commercial banks to implement green credit policies, the local government may inevitably produce some deviated behaviors such as inadequate supervision and intervention due to financial pressure and other self-interest factors. Accordingly, local government should consolidate regulatory responsibilities and establish relevant evaluation and accountability mechanisms to promote the implementation of green credit. At the same time, the government's support for green credit should be kept within a certain range. In the context of limited financial resources, the superior authorities need to fully conduct investigations and studies, set up scientific and reasonable incentive policies, and make a balance between the subjects to be regulated.

Second, when the superior department is committed to improving the convergence rate of subject strategy, the punishment mechanism can exert a better regulatory effect. Although incentives such as tax cuts and financial subsidies can effectively shorten the time when loan enterprises and banks reach the state of full cooperation, they all come at the cost of a slight delay in the time when the government reaches full support, and the effect of regulation is not significant. However, when superior authorities take punitive measures to increase the risk cost of noncooperation among the three parties, the time when local government, commercial banks, and loan enterprises reach the fully cooperative state is significantly earlier, and local government is most sensitive to risk costs. Therefore, according to the priority of variable adjustment, the superior authorities should first increase the punishment on local government and increase the risk cost of dereliction of duty such as inadequate intervention and insufficient support. And then, it is necessary to increase the penalties for commercial banks with illegal lending and enterprises with nongreen production, strengthen the responsibility assessment on banks' green credit business, timely disclose enterprises' environmental information, and urge them to assume social responsibilities.

Lastly, when the superior department hopes to improve the changing degree of subject strategy, both reward mechanism and punishment mechanism can play an obvious regulatory role. The financial subsidy incentives for commercial banks, as well as the punishment on unqualified governments and nongreen production enterprises all show good results in increasing the proportion of green credit participants. So, when building a long-term mechanism for green credit, the relevant departments should combine reward and punishment, give priority to punishment, and supplement with rewards. It is vitally important to impose severe accountability and punishment for illegal lending by banks and illegal production by polluting enterprises. At the same time, under the premise of sustainability, the government should establish a reasonable financial subsidies system and actively lead the flow of social funds to the enterprises with green production and the banks with green credit.

In addition, there are still some limitations in this study: (1) in reality, the implementation process of green credit is subject to numerous and complex random disturbance, but the explanation and analysis of random factors in this article are not comprehensive enough, which can be the direction of future research; (2) in the simulation stage, it is difficult to obtain actual case data, so the research results can only reflect the general situation of the players' strategy evolution; and (3) the variable setting in this article is based on common scenarios. To be closer to reality, perhaps we can try to refine variables and consider more complex green credit scenarios.

\section{Data Availability}

The data used to support the findings of this study are included within the article.

\section{Conflicts of Interest}

The authors declare that there are no conflicts of interest regarding the publication of this paper.

\section{Acknowledgments}

This work was supported by National Natural Science Foundation of China (Grants nos. 11671229 and 11871309); National Key R\&D Program of China (Grant no. 2018YFA0703900); and Natural Science Foundation of Shandong Province of China (Grants nos. ZR2020MA032 and ZR2019MA013).

\section{References}

[1] M. Aizawa and C. F. Chaofei Yang, "Green credit, green stimulus, green revolution? China's mobilization of banks for environmental cleanup," The Journal of Environment \& Development, vol. 19, no. 2, pp. 119-144, 2010.

[2] L. He, L. Zhang, Z. Zhong, D. Wang, and F. Wang, "Green credit, renewable energy investment and green economy development: empirical analysis based on 150 listed companies of China," Journal of Cleaner Production, vol. 208, pp. 363-372, 2019.

[3] F. Wang, S. Yang, A. Reisner, and N. Liu, "Does green credit policy work in China? The correlation between green credit 
and corporate environmental information disclosure quality," Sustainability, vol. 11, no. 3, p. 733, 2019.

[4] H. Zhang, X. Xu, W. Liu, and Z. Jia, "Green supply chain decision modeling under financial policy, with or without uniform government emission reduction policy," Managerial and Decision Economics, vol. 41, no. 6, pp. 1040-1056, 2020.

[5] B. Zhang, Y. Yang, and J. Bi, "Tracking the implementation of green credit policy in China: top-down perspective and bottom-up reform," Journal of Environmental Management, vol. 92, no. 4, pp. 1321-1327, 2011.

[6] C. H. Xue and P. Wei, "Research on green credit strategy of China's commercial banks based on game model," Financial Theory \& Practice, vol. 5, pp. 75-81, 2020.

[7] Z. D. Wang, B. Zhao, and S. Y. Lv, "Study on the implementation mechanism of the green-credit policy from the perspective of evolutionary game theory," Financial Regulation Research, vol. 6, pp. 80-97, 2012.

[8] S. M. Li, "An evolutionary game analysis of green credit under the reward and punishment mechanism," Financial Regulation Research, vol. 5, pp. 83-98, 2019.

[9] Y. S. Zhou, S. H. Liang, S. Q. Liu, and J. Wang, “The game study of establishing green supply chain from the perspective of green credit," Journal of Management Sciences in China, vol. 20, no. 12, pp. 87-98, 2017.

[10] F. X. Han, H. J. Xiao, D. H. Peng, and S. Y. Huo, "Development motive investigation of green finance under the new normal economy-_based on a three-party game among the government, bank and enterprises," Review of Economy and Management, vol. 33, no. 5, pp. 88-94, 2017.

[11] M. Liu and L. N. Hao, "Evolutionary game analysis of various participants from the perspective of green development," Modernization of Management, vol. 38, no. 5, pp. 95-98, 2018.

[12] D. Foster and P. Young, "Stochastic evolutionary game dynamics*," Theoretical Population Biology, vol. 38, no. 2, pp. 219-232, 1990.

[13] C. Taylor, D. Fudenberg, A. Sasaki, and M. Nowak, "Evolutionary game dynamics in finite populations," Bulletin of Mathematical Biology, vol. 66, no. 6, pp. 1621-1644, 2004.

[14] L. A. Imhof and M. A. Nowak, "Evolutionary game dynamics in a Wright-Fisher process," Journal of Mathematical Biology, vol. 52, no. 5, pp. 667-681, 2006.

[15] Y. Xu, B. Hu, and R. Qian, "Analysis on stability of strategic alliances based on stochastic evolutionary game including simulations," Systems Engineering-Theory \& Practice, vol. 31, no. 5, pp. 920-926, 2011.

[16] H. L. Sun, X. Q. Wang, and Y. F. Xue, "Stochastic evolutionary game model for unexpected incidents involving mass participation based on different scenarios," Operations Research and Management Science, vol. 25, no. 4, pp. 23-30, 2016.

[17] J. X. Miao, D. C. Huang, and C. Z. Zhang, "Risk behavior mechanism and simulation analysis of major projects based on stochastic evolutionary game theory," Mathematics in Practice and Theory, vol. 49, no. 10, pp. 106-113, 2019.

[18] Y. T. He and F. J. Xie, "Stochastic evolutionary game analysis on the industry-university-institute collaboration innovation," Management Review, vol. 32, no. 6, pp. 150-162, 2020.

[19] J. Q. Li, H. Ren, and J. Zhen, "Stochastic evolutionary game analysis of multiple supervision paths of enterprise R\&D manipulation," Chinese Journal of Management Science, vol. 25, pp. 1-15, 2019.

[20] J. Q. Li, H. Ren, C. C. Zhang, Q. X. Li, and K. F. Duan, "Substantive innovation or strategic innovation? Research on multiplayer stochastic evolutionary game model and simulation," Complexity, vol. 2020, Article ID 9640412, 12 pages, 2020.

[21] J. M. Smith and G. R. Price, "The logic of animal conflict," Nature, vol. 246, no. 5427, pp. 15-18, 1973.

[22] S. Y. Xie, Economic Game Theory, Fudan University Press, Shanghai, China, 2016.

[23] E. Amann and A. Possajennikov, "On the stability of evolutionary dynamics in games with incomplete information," Mathematical Social Sciences, vol. 58, no. 3, pp. 310-321, 2009.

[24] C. T. H. Baker and E. Buckwar, "Exponential stability in $p$-th mean of solutions, and of convergent Euler-type solutions, of stochastic delay differential equations," Journal of Computational and Applied Mathematics, vol. 184, no. 2, pp. 404427, 2005.

[25] S. G. Hu, C. M. Huang, and F. K. Wu, Stochastic Differential Equation, Science Press, Beijing, China, 2008.

[26] P. D. Taylor and L. B. Jonker, "Evolutionary stable strategies and game dynamics," Mathematical Biosciences, vol. 40, no. 12, pp. 145-156, 1978.

[27] C. Graham and D. Talay, Stochastic Simulation and Monte Carlo Methods: Mathematical Foundations of Stochastic Simulation, Springer, Berlin, Germany, 2013. 